\title{
Ocular argyrosis secondary to long-term ingestion of silver nitrate salts
}

This article was published in the following Dove Press journal:

Clinical Ophthalmology

4 December 2012

Number of times this article has been viewed

\author{
Kesenia Stafeeva \\ Michael Erlanger \\ Raul Velez-Montoya \\ Jeffrey L Olson \\ Department of Ophthalmology, \\ University of Colorado School \\ of Medicine, Rocky Mountain Lions \\ Eye Institute, Colorado, CO, USA
}

Correspondence: Jeffrey L Olson

1675 Aurora Court,

Aurora CO 80204, USA

$\mathrm{Tel}+\mathrm{I} 7208482500$

Fax +I $72084850 \mid 4$

Email jeffrey.olson@ucdenver.edu

\begin{abstract}
This case report describes the clinical, autofluorescence, and optical coherent tomography findings in a patient with panocular argyrosis secondary to chronic intake of diluted silver nitrate salts in his water supply. An 86-year-old Caucasian male with a distinctive gray-bluish hue of the skin presented to our clinic, having developed a slow decrease in visual acuity in both eyes and nyctalopia for the past 2 years. Based on the patient's history of chronic intake of silver nitrate salts and a positive skin biopsy (performed by the dermatology department, data not shown), a diagnosis of panocular argyrosis was made. Fluorescein angiography showed choroidal blockage with a completely dark choroid. Fundus autofluorescence was within normal limits. Optical coherent tomography showed multiple excrescences of retinal pigment epithelium in both eyes. Although the drusen-like changes on fundus examination and retinal pigment epithelium changes may account for the diminished vision, the presence of concomitant nyctalopia suggests underlying damage of the photoreceptors.
\end{abstract}

Keywords: silver nitrate, argyria, ocular argyrosis, fundus autofluorescence, optical coherent tomography

\section{Introduction}

Silver is a naturally occurring element with various physical properties, such as high thermal and electrical conductivity, ductility, hardness, malleability, and even antimicrobial ability. Silver was known and used by ancient people as early as $4000 \mathrm{BC}$, along with gold and copper. ${ }^{1}$ Silver now has a wide variety of applications, including in photography, soldering, metallurgy, medicine and dentistry, water sanitation, jewelry, coins, silverware, and mirrors. ${ }^{2,3}$ Silver nitrate $\left(\mathrm{AgNO}_{3}\right)$ is a soluble silver salt used in medications to treat intestinal and oral ulcers as well as to control gingival bleeding. Another relatively common use of silver nitrate is water purification, as in the case reported here. Silver-containing compounds should be used with caution, given the risk of toxicity. ${ }^{3}$

Generalized argyria is a rare dermatological disorder caused by silver granule deposits in the skin and mucous membranes, due to chronic exposure of patients to silver-containing compounds. ${ }^{4}$ Persistent respiratory, topical, or oral exposure can lead to deposition of silver in the eye and periocular tissue, and a condition known as ocular argyrosis. ${ }^{5}$ This pathology has been described previously. ${ }^{5-8}$ The clinical presentation includes gray-blue discoloration of the periorbital skin, bulbar and palpebral conjunctiva, and lacrimal sac, as well as cornea opacities and cataracts. ${ }^{5-8}$ The latter are the main causes of specialist referrals. ${ }^{8}$ Findings at the posterior pole include a leopard spot pattern of the macula and a dark choroid, observed by means of red-monochromatic fundus pictures 
and fluorescein angiography, respectively. ${ }^{9}$ Although there are no visual symptoms in most reported cases, there are a few case reports in which patients complained of nyctalopia. ${ }^{5}$ However, patients undergoing electrophysiologic testing did not demonstrate functional deficits in scotopic or photopic electroretinography, nor were there any abnormalities on color vision testing. ${ }^{5}$

In the following case report, we describe a patient who developed ocular argyrosis after chronic ingestion of silver nitrate in his personal water supply. In order to expand the available data regarding this condition, we include a description of fundus autofluorescence and optical coherent tomography findings.

\section{Case report}

An 86-year-old Caucasian male with a previous medical history remarkable for normal pressure hydrocephalus after ventricular shunt placement, early dementia, and skin argyria ( 2 years) was seen at the ophthalmology clinic, complaining of slowly decreasing visual acuity and nyctalopia in both eyes (OU). According to the primary caretaker, the patient had been drinking water from a well and purifying it with silver nitrate compounds for a period of at least 13 years, on the basis of advice from an alternative medicine professional, who recommended their use as antimicrobial agents and as a water purification method. The patient was subsequently advised by dermatology to suspend his silver nitrate intake 2 years prior to presentation to us. During the initial consultation, the patient's appearance was remarkable for a generalized gray-bluish hue of the skin and fingernails, more pronounced on the face, periorbital area, and forearms (Figure 1). Best corrected visual acuity was right eye (OD) 20/40 and left eye (OS) 20/50. Intraocular pressure OU was $14 \mathrm{mmHg}$. There was no afferent pupillary defect and confrontational vision fields were full in both eyes. Color vision was $8 / 8$ on the Ishihara color plate test. Both palpebral and bulbar conjunctiva had a purple-blue hue, but were normally vascularized and showed no epithelial defect. The palpebral portion of the main lacrimal gland also had a purple-bluish hue. The lacrimal punctum was permeable. Both corneas were clear and mild bilateral nuclear sclerotic cataracts were present. Fundus examination was remarkable for retinal pigment epithelium (RPE) changes and drusen formation on macula OU, consistent with age-related macular degeneration (Figure 2).

Fluorescein angiography showed choroidal blockage with completely dark choroid in later phases in both eyes. Areas of dot hyperfluorescence in the macula were present,

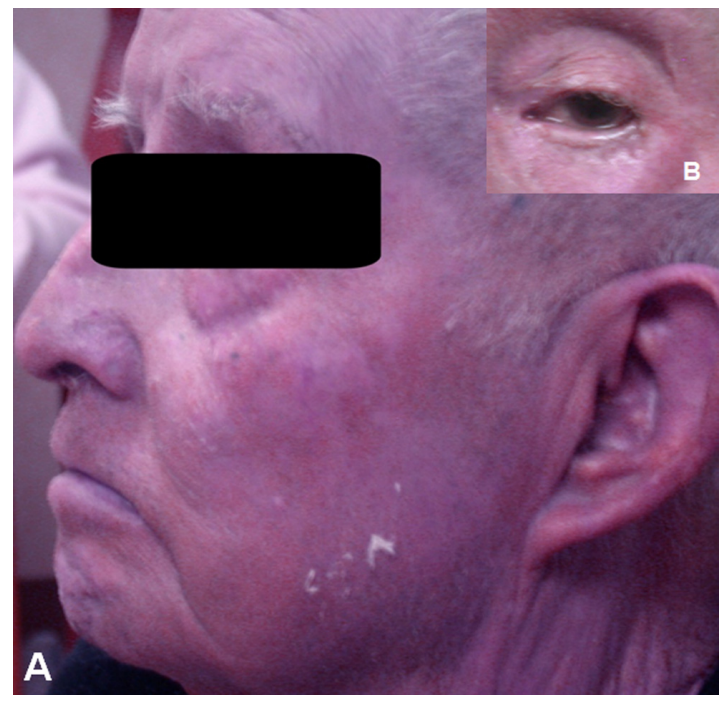

Figure I Clinical picture of the patient's face showing the gray-bluish hue of the skin of the face, scalp, and neck (A), including the periocular region, conjunctiva, and sclera (B).

corresponding to the drusenoid deposits. Normal perfusion of the retinal vasculature was observed. Fundus autofluorescence did not show any hyperautofluorescence or hypoautofluorescence of the macula. Spectralis domain optical coherence tomography showed multiple excrescences of RPE

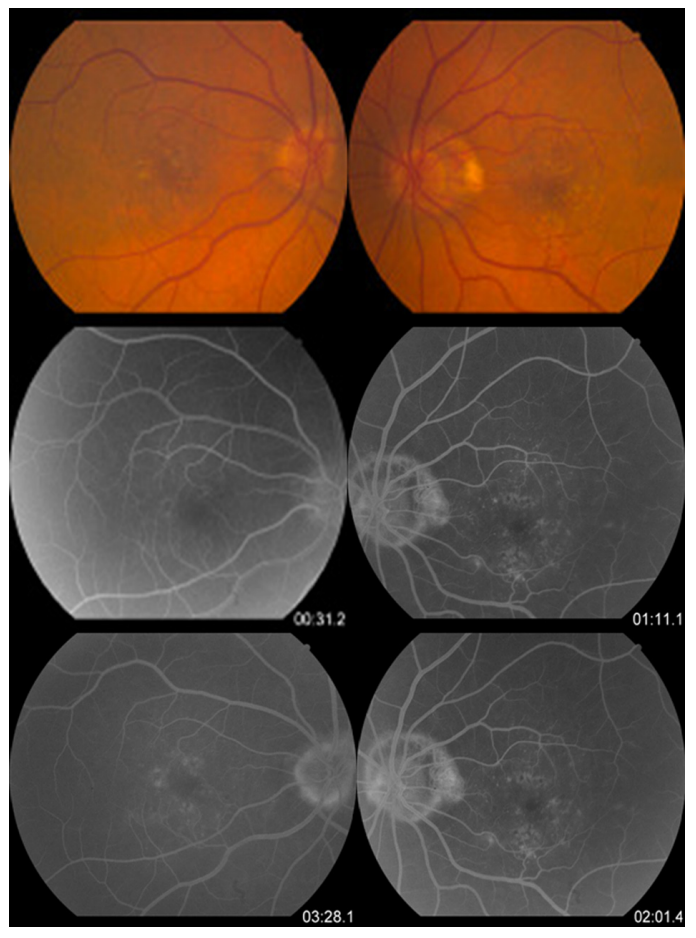

Figure 2 Fundus color photographs and early and late phases of fluorescein angiography.

Notes: In the color photographs, there is evidence of pigmentary changes at the level of the retinal pigmented epithelium and drusen formation in both macula. Fluorescein angiography shows early and late hyperfluorescence probably due to the aforementioned changes. 
in both eyes, most likely representing drusen from age-related macular degeneration (Figure 3). An electroretinogram was obtained because of the patient's symptoms of nyctalopia, and revealed normal scotopic and photopic amplitudes and latency, as well as normal oscillatory potentials and $30 \mathrm{~Hz}$ flicker testing (data not shown).

\section{Discussion}

In this case report, we describe the clinical and ancillary test findings in a patient with ocular argyrosis. It is important to mention that, although there are previous reports and clinical descriptions of the anterior segment alterations and periocular skin deposits, there are relatively few descriptions of involvement of the posterior pole. The interesting finding of dark choroid, which occurs when the normal choroidal background fluorescence is blocked, was made in our patient on fluorescein angiography. Similar findings have been reported by Cohen et al. ${ }^{9}$ A dark or "silent" choroid is most commonly associated with Stargardt's disease and other posterior retinal dystrophies. ${ }^{9}$ The pathophysiology in patients with silver accumulation which leads to this angiographic finding is not understood as yet. Wislocki and Ladman conducted an experiment in albino rats involving giving them water containing silver nitrate for a period of 6 months to a year and trying to demonstrate the blood-ocular barrier. They reported histopathologic data showing that silver accumulated in two regions of the eye, ie, the ciliary processes and Bruch's membrane. ${ }^{10}$ They also noted that the longer silver nitrate was administered, the greater the amount that accumulated. Spencer et al performed a histopathologic examination in a patient with systemic argyrosis and found that brown-black silver pigment was present in three locations of the eye, ie, Bruch's membrane, Bowman's membrane, and Descemet's membrane, with the majority of deposition occurring in Bruch's membrane. ${ }^{11}$

Therefore, the question arises as to how systemic argyrosis causes findings of dark choroid on fluorescein angiography, as in our patient. One of the mechanisms proposed is that accumulation of silver pigment deposits in large amounts in Bruch's membrane causes absorption

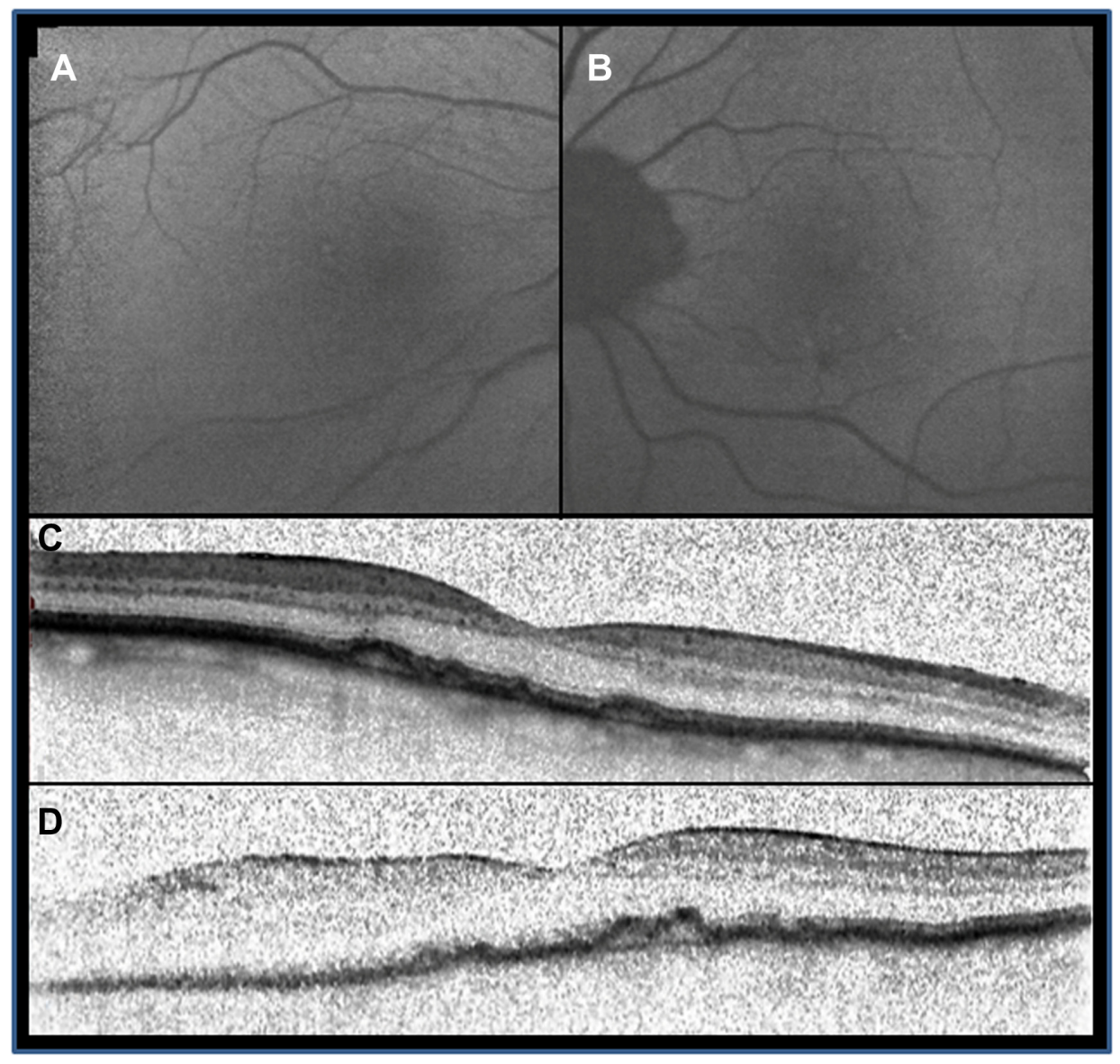

Figure 3 Fundus autofluorescence images (A and $\mathbf{B}$ ) and optical coherent tomography images (C and $\mathbf{D})$.

Notes: The images show no evidence of metabolic dysfunction in the retinal pigmented epithelium. Optical coherence tomography shows small pigment epithelial detachments secondary to drusen. 
of short-wavelength light during fluorescein angiography, which could be responsible for the phenomenon of dark choroid. $^{9-11}$ Furthermore, in the same study series, red light monochromatic pictures were taken, which utilize a long wavelength to bypass RPE and visualize the choroidal vasculature in normal subjects. However, the choroidal vasculature could not be visualized in any of the six cases from that study utilizing red light pictures, meaning that the long wavelengths were blocked as well. Thus, it has been proposed that silver deposits block all light, from short to long wavelengths. ${ }^{9-11}$

Given the results above, it is reasonable to question whether silver might accumulate not only in Bruch's membrane but also in RPE cells. However, a previous histopathologic study in albino rats did not show any accumulation of silver deposits in RPE cells, ${ }^{10}$ and furthermore, the fundus autofluorescence images from our patient did not show any signs of RPE damage. To our knowledge, there is only one previous report describing choroidal and retinal changes in patients with ocular argyrosis by means of fundus photographs and fluorescein angiography. ${ }^{9}$ In this case report, we expand the available information regarding changes in the retina and RPE. Our patient underwent noninvasive evaluation for retinal pigment abnormalities with fundus autofluorescence, which uses a confocal scanning laser ophthalmoscope to detect accumulations, typically of lipofuscin granules, in RPE cells. There were no abnormalities noted other than mild changes of dry macular degeneration.

The condition of generalized and ocular argyrosis remains rare. However, there are numerous homeopathic remedies containing silver compounds. Ophthalmologist and retinal specialists should be aware that conditions other than Stargardt's disease can cause findings of dark choroid on fluorescein angiography.

\section{Disclosure}

The authors report no conflicts of interest in this work.

\section{References}

1. Alexander JW. History of the medical use of silver. Surg Infect (Larchmt). 2009;10(3):289-292.

2. Pala G, Fronterre A, Scafa F, et al. Ocular argyrosis in a silver craftsman. J Occup Health. 2008;50(6):521-524.

3. Drake PL, Hazelwood KJ. Exposure-related health effects of silver and silver compounds: a review. Ann Occup Hyg. 2005;49(7):575-585.

4. Sanchez-Pulgarin M, Matilla M, Martinez-de-la-Casa JM, Jerez M, Benitez-del-Castillo JM. Confocal microscopy in ocular argyrosis. Cornea. 2010;29(5):580-582.

5. Moss AP, Sugar A, Hargett NA, Atkin A, Wolkstein M, Rosenman KD. The ocular manifestations and functional effects of occupational argyrosis. Arch Ophthalmol. 1979;97(5):906-908.

6. Scroggs MW, Lewis JS, Proia AD. Corneal argyrosis associated with silver soldering. Cornea. 1992;11(3):264-269.

7. Sanchez-Huerta V, De Wit-Carter G, Hernandez-Quintela E, Naranjo-Tackman R. Occupational corneal argyrosis in art silver solderers. Cornea. 2003;22(7):604-611.

8. Gallardo MJ, Randleman JB, Price KM, et al. Ocular argyrosis after long-term self-application of eyelash tint. Am J Ophthalmol. 2006;141(1):198-200.

9. Cohen SY, Quentel G, Egasse D, Cadot M, Ingster-Moati I, Coscas GJ. The dark choroid in systemic argyrosis. Retina. 1993;13(4):312-316.

10. Wislocki GB, Ladman AJ. The demonstration of a blood-ocular barrier in the albino rat by means of the intravitam deposition of silver. J Biophys Biochem Cytol. 1955;1(6):501-510.

11. Spencer WH, Garron LK, Contreras F, Hayes TL, Lai C. Endogenous and exogenous ocular and systemic silver deposition. Trans Ophthalmol Soc U K. 1980;100(Pt 1):171-178.
Clinical Ophthalmology

\section{Publish your work in this journal}

Clinical Ophthalmology is an international, peer-reviewed journal covering all subspecialties within ophthalmology. Key topics include: Optometry; Visual science; Pharmacology and drug therapy in eye diseases; Basic Sciences; Primary and Secondary eye care; Patient Safety and Quality of Care Improvements. This journal is indexed on Submit your manuscript here: http://www.dovepress.com/clinical-ophthalmology-journal

\section{Dovepress}

PubMed Central and CAS, and is the official journal of The Society of Clinical Ophthalmology (SCO). The manuscript management system is completely online and includes a very quick and fair peer-review system, which is all easy to use. Visit http://www.dovepress.com/ testimonials.php to read real quotes from published authors. 